International

Medical Society

http://imedicalsociety.org
Vol. 9 No. 160

doi: $10.3823 / 2031$

\section{Paraquat Tongue: Rebirth of Paraquat Intoxication}

Tai-You Guo1, Chu-Yu Hsu', Kuo-An Wu', Wen-Fang Chiang ${ }^{1}$, Jenq-Shyong Chan ${ }^{1}$, Po-Jen Hsiao ${ }^{1,2}$

1 Division of Nephrology, Department of Internal Medicine, Taoyuan Armed Forces General Hospital, Taiwan.

2 Division of Nephrology, Department of Internal Medicine, Tri-Service General Hospital, National Defense Medical Center, Taipei, Taiwan.

\section{Contact information:}

\section{Po-Jen Hsiao, MD.}

Address: Division of Nephrology, Department of Internal Medicine,Taoyuan Armed Forces General Hospital, Taiwan. No.168, Zhongxing Rd., Longtan Dist., Taoyuan City 325, Taiwan, R.O.C. Tel: +886-3-4799595.

Fax: $+886-3-4801625$.

\section{a2005a660820@yahoo.com.tw}

\section{Keywords}

Paraquat Tongue; Paraquat Intoxication.

\title{
Introduction
}

The main causes of pesticide poisoning in Taiwan are paraquat, organic phosphates, glyphosate and carbamates [1, 2]. Paraquat, 1, '-dimethyl4,4 '-bipyridinium dichloride, is the one of the most widely used herbicides in the world. Paraquat is a rapidly-acting, non-selective herbicide and relatively inexpensive. It is toxic to human beings and animals by its redox activity, which products superoxide anion, potentially leading to acute respiratory distress syndrome and acute kidney injury [3, 4].

Paraquat is rapidly absorbed from ingestion, dermal exposure and inhalation and can be detected within 1 hour from serum and uri- 
ne. According to data published by Proudfoot et al. (1979), Proudfoot (1995) and Smith (1988b), peak concentrations (Cmax) in humans are attained within 2 hours to 4 hours after ingestion [6, 7]. Irrespective of the route of administration, lung and kidney are the organs showing the highest concentrations of paraquat [7-9]. Preferential accumulation in the lung is increasing toxicity due to superoxide anion. Over a period of hours to days, these processes cause multi-organs failure. The most affected organs are those with oxygen tension, high blood flow, and energy requirements, in particular the heart, lung, kidney, and liver. In general, urine paraquat test is useful for screening paraquat poisoning [10]. Management of paraquat intoxication usually depends on the amount ingested and the time elapsed since the exposure.

\section{Case Report}

A 39-year-old male was brought to our emergency department (ED) 2 hours after attempting suicide by ingesting unknown herbicides. He has history of depressive disorders without regular follow-up. His Glasgow Coma Scale (GCS) is E4V5M6. His blood pressure was 130/96 mmHg, pulse rate was 82 beats/min, and respiratory rate was 18 breaths/min. Initial laboratory examinations revealed normal kidney function tests and normal serum electrolytes. Unknown drugs screening test of urine, including benzodiazepine, tricyclic antidepressants, barbiturates, cocaine, acetaminophen, tetrahydrocannabinol and phencyclidine, showed negative results. Physical examinations revealed mild green-blue color over distal phalanx of right index finger (Figure 1). In addition, mild reddish without obvious ulceration was noted over the apex of tongue. Chest radiography was unremarkable. Urine paraquat test was also performed but revealed negative findings at initial 1 hour and 2 hours after arrival of ED. He received gastric lavage with NG-tube, and only some yellowish gastric juice was found from NG tube.
The patient finally told the physician that he took a small amount of paraquat (24\%) through his right finger. The diagnosis of paraquat intoxication was made based on history taking and physical examinations. Then serum paraquat test was checked at ED. After admission, he received charcoal hemoperfusion therapy for 2 times. The apex region of tongue revealed mild reddish at day 3 (Figure 2 ) and obvious ulcerations at day 6 (Figure 3) after admission. Initial

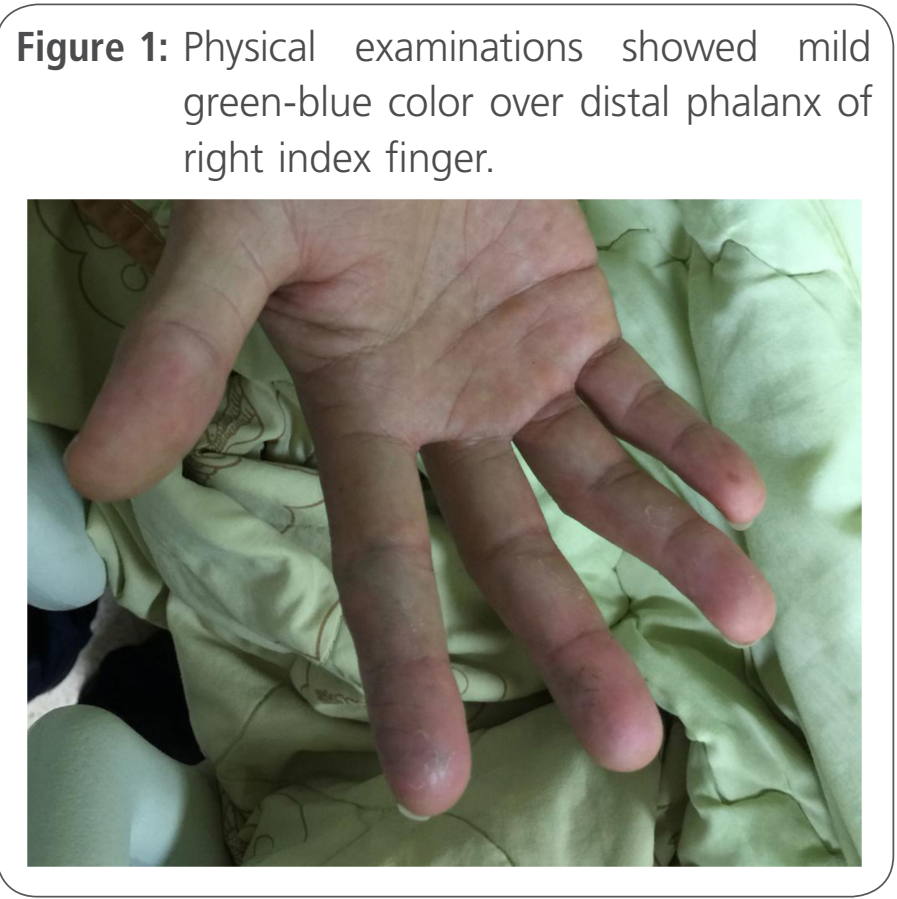

Figure 2: The apex region of tongue showed mild reddish at day 3 .

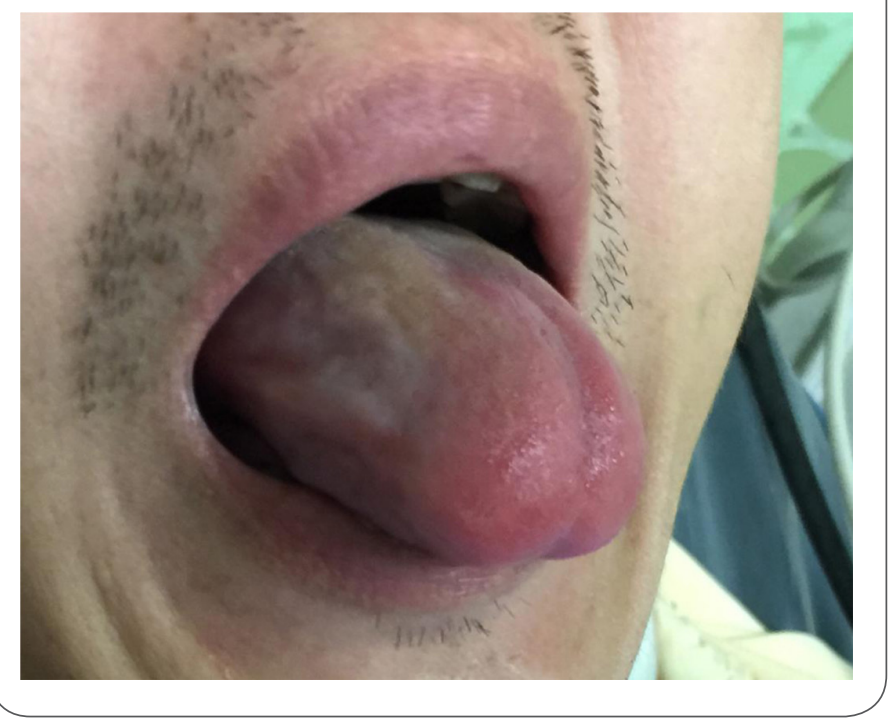


serum paraquat test at ED was positive and the concentration was $0.1 \mu \mathrm{g} / \mathrm{ml}$. Following kidney function tests and chest radiographies showed normal. The results of serials of serum paraquat concentrations were undetectable after hemoperfusion. Lastly, he was discharged after 10 days in hospital. No obvious respiratory sequelae and kidney injury were found with 6-month follow-up.

Figure 3: The apex region of tongue showed obvious ulcerations at day 6 .

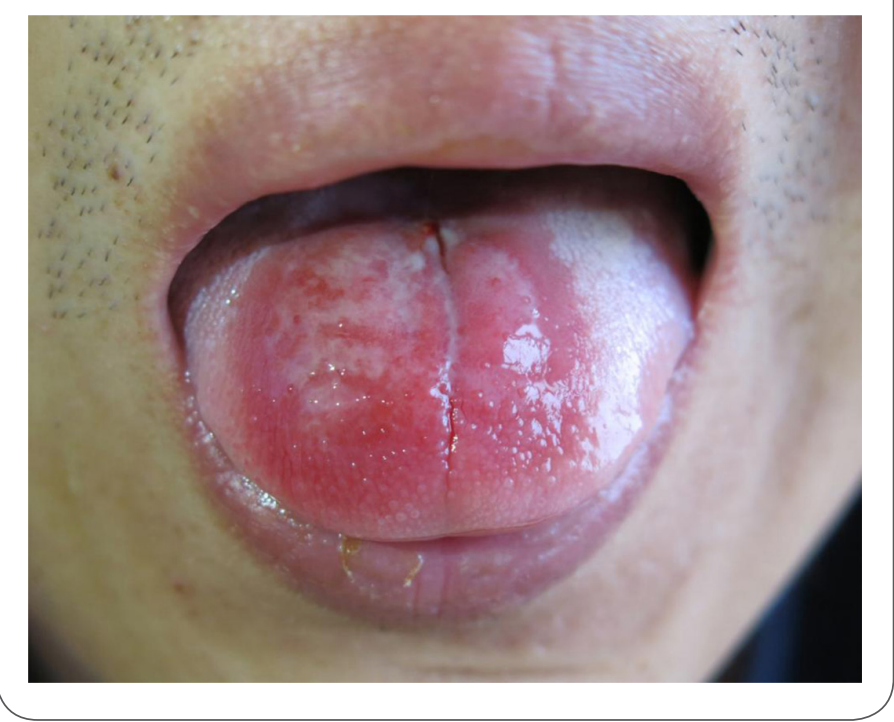

\section{Discussion}

Paraquat intoxication is life-threatening and can cause major effects on gastrointestinal tract, lung, liver, and kidney. The Median Lethal Dose (LD50) in human beings is approximately $35 \mathrm{mg} / \mathrm{kg}$, which translates into as little as $8-12 \mathrm{ml}$ of a $24 \%$ solution [11]. The gastrointestinal tracts such as tongue, mouth, pharynx, esophagus, stomach and intestine are the most initial sites of toxicity, which is manifested by edema, swelling, and painful ulceration. In some severe cases, centrizonal hepatocellular injury can occur, resulting in elevated bilirubin and enzymes like aspartate transaminase (AST), alanine aminotransaminase (ALT) and lactate dehydrogenase (LDH) [12]. The hepatic injury from paraquat can be severe enough to cause jaundice. However, he- patotoxicity is rarely a major determinant to clinical outcome. On the contrary, acute kidney injury plays a critical role in determining the clinical outcome [12].

Pulmonary complication also represents the most lethal and least treatable manifestation. Both type I and || pneumatocytes appear to selectively accumulate paraquat. Biotransformation of paraquat in these cells causes free radical production with promotion lipid peroxidation and cell injury [13, 14]. There is a progressive decline in arterial oxygen tension and $\mathrm{CO} 2$ diffusion capacity. Cyanosis and dyspnea reflect deteriorating gas exchange in the damaged lung. In addition, frothy sputum is the early and principal manifestation of pulmonary edema. Such a serious dysfunction of gas exchange results eventual death due to hypoxemia. Acute pulmonary edema and early lung damage can occur within few hours to days after ingestion [13, 14]. In clinical practice, routine investigations such as liver function tests, kidney function tests, and electrolytes are checked only to monitor baseline status of the patient. Several studies predicted survival rates in patients with paraquat intoxication by using plasma paraquat concentrations and/or clinical criteria [16-19].

Paraquat is not metabolised and nearly excreted unchanged in the urine, it can be easily detected by qualitative urine analysis. A semi-quantitative test using bicarbonate and sodium dithionite can be used as a bedside test to confirm systemic paraquat toxicity [19]. In an alkaline medium, sodium dithionite reduces paraquat to a blue radical. If the urine paraquat concentration is more than 1 $\mu \mathrm{g} / \mathrm{ml}$, the urine will appear blue and this finding alone indicates a very poor prognosis [20]. However, negative urine paraquat test could also be fatal [21]. To date, hemoperfusion is proven to be better than homodialysis in treating patients with paraquat poisoning. Hemoperfusion can decrease mortality rates within 6-12 hours after paraquat exposure. Cyclophosphamide, methylprednisolone, 
dexamethasone and vitamine $C$ have some therapeutic effects $[20,22,23]$.

\section{Conclusion}

The present case highlights the importance that physicians should be alert to the possibility of acute paraquat poisoning in high risk patients presenting with unknown skin lesions and mucosal ulcerations. The absence of paraquat in urine could also be fatal. Early recognition and the rapid treatment of paraquat intoxication are imperative, even in cases with negative urine paraquat tests.

\section{Reference}

1. Yang CC, Wu JF, Ong HC, Hung SC, Kuo YP, Sa CH, et al. Taiwan National Poison Center: epidemiologic data 1985-1993. J Toxicol Clin Toxicol. 1996; 34(6): 651-63

2. Hung DZ, Yang CC, Ong HC, Wu JF, Sa CH, Chen SS, et al. The present and feature of poison control center in Taiwan. J Toxicol Sci. 1998; 23 Suppl 2: 280-3.

3. Bonneh-Barkay D, Reaney SH, Langston WJ, Di Monte DA. Redox cycling of the herbicide paraquat in microglial cultures. Brain Res Mol Brain Res. 2005; 134(1): 52-6.

4. Adam A, Smith LL, Cohen GM. Langston WJ, Di Monte DA. An assessment of the role of redox cycling in mediating the toxicity of paraquat and nitrofurantoin. Environ Health Perspect. 1990; 85: 113-7.

5. Price LA, Newman KJ, Clague $A E$, Wilson PR, Wenck DJ. Paraquat and diquat interference in the analysis of creatinine by the Jaffé reaction. Pathology. 1995; 27(2): 154-6.

6. Proudfoot AT, Stewart MS, Levitt T, Widdop B. Paraquat poisoning: significance of plasma-paraquat concentrations. Lancet. 1979; 2(8138): 330-2.

7. Murray RE, Gibson JE. A comparative study of paraquat intoxication in rats, guinea pigs and monkeys. Exp Mol Pathol. 1972; 17(3): 317-25.

8. Sharp CW, Ottolenghi A, Posner HS. Correlation of paraquat toxicity with tissue concentrations and weight loss of the rat. Toxicol Appl Pharmacol. 1972; 22(2): 241-51

9. llett KF, Stripp B, Menard RH, Reid WD, Gillette JR. Studies on the mechanism of the lung toxicity of paraquat: comparison of tissue distribution and some biochemical parameters in rats and rabbits. Toxicol Appl Pharmacol. 1974; 28(2): 216-26.

10. Gil HW, Hong JR, Jang SH, Hong SY. Diagnostic and therapeutic approach for acute paraquat intoxication. J Korean Med Sci. 2014; 29(11):1441-9

11. U.S. National Library of Medicine. Hazardous Substances Databank. Bethesda, MD, 1995. 10-9.
12. Mullick FG, Ishak KG, Mahabir R, Stromeyer FW. Hepatic injury associated with paraquat toxicity in humans. Liver. 1981; 1(3): 209-21.

13. Smith $P$, Heath D, Kay JM. The pathogenesis and structure of paraquat-indu ced pulmonary fibrosis in rats. J Pathol. 1974; 114(2): 57-67.

14. Honoré $P$, Hantson $P$, Fauville JP, Peeters $A$, Manieu P. Paraquat poisoning. "State of the art". Acta Clin Belg. 1994; 49(5): 220-8.

15. Nordquist RE1, Nguyen $H$, Poyer JL, Carubelli R. The role of free radicals in paraquat-induced corneal lesions. Free Radic Res. $1995 ; 23(1): 61-71$

16. Ikebuchi J. Evaluation of paraquat concentrations in paraquat poisoning. Arch Toxicol. 1987; 60(4): 304-10.

17. Yoon SC. Clinical outcome of paraquat poisoning. Korean J Intern Med. 2009; 24(2): 93-4.

18. Senarathna $L$, Eddleston $M$, Wilks MF, Woollen $B H$, Tomenson JA, Roberts DM, el al. Prediction of outcome after paraquat poisoning by measurement of the plasma paraquat concentration. QJM. 2009; 102(4): 251-9.

19. Liu Z, Liu D, Zhang X, Wang H, Hao F. Prognosis value of urine paraquat semi-quantitative in the patients with acute paraquat poisoning. Zhonghua Lao Dong Wei Sheng Zhi Ye Bing Za Zhi. 2014; 32(5): 378-80. [Article in Chinese]

20. Gawarammana IB1, Buckley NA. Medical management of paraquat ingestion. Br J Clin Pharmacol. 2011; 72(5):745-57.

21. Monteiro R, Correia L, Simão A, Carvalho A, Costa JN. Negative paraquaturia does not exclude paraquat fatal poisoning. Acta Med Port. 2011 ;24 Suppl 3: 645-8.

22. Peng ZY, Chang P, Wang H, Cen ZR, Zhou J, Liu ZG. Intensive hemoperfusion and long-term hemofitration for treatment of paraquat poisoning: a case report, Nan Fang Yi Ke Da Xue Xue Bao. 2015; 35(10): 1515-8. [Article in Chinese]

23. Chang JB, Lin CC, Chiou JF, Mau SY, Liu TZ, Chen CH. Treatment of acute paraquat intoxication using recommended megadose of vitamin C: a reappraisal. Free Radic Res. 2013; 47(12): 9911001.

\section{Publish in International Archives of Medicine}

International Archives of Medicine is an open access journal publishing articles encompassing all aspects of medical science and clinical practice. IAM is considered a megajournal with independent sections on all areas of medicine. IAM is a really international journal with authors and board members from all around the world. The journal is widely indexed and classified Q1 in category Medicine. 